Article

\title{
Optimal Use of Agricultural Water and Land Resources through Reconfiguring Crop Planting Structure under Socioeconomic and Ecological Objectives
}

\author{
Qian Tan ${ }^{1, *}$, Shan Zhang ${ }^{1}$ and $\operatorname{Ran~Li}^{2}$ \\ 1 College of Water Resources and Civil Engineering, China Agricultural University, Beijing 100083, China; \\ zhangshan@cau.edu.cn \\ 2 State Key Laboratory of Hydraulics and Mountain River Engineering, Sichuan University, \\ Chengdu 610065, China; liran@scu.edu.cn \\ * Correspondence: qian_tan@cau.edu.cn; Tel.: +86-6273-8635
}

Received: 5 May 2017; Accepted: 29 June 2017; Published: 4 July 2017

\begin{abstract}
Many economic, social and ecological problems can be attributed to the scarcity and mismanagement of water and land resources. In this study, a multi-objective fuzzy-robust programming (MOFRP) method was developed for supporting the optimal use of land and water resources in agriculture. MOFRP improved existing methods through taking ecological services of crop cultivation into account. It was also capable of reflecting fuzziness in preferences, priorities and parameters that were largely neglected in previous agricultural decision making. This method was applied to address a case in arid northwestern China. Optimal plans of crop cultivation reconfiguration were generated for sustaining local development under economic, ecological and social objectives as well as physical restraints in water and land resources. Compared to the status quo, the optimized plan would increase economic and ecological benefits by $12.2 \%$ and $18.8 \%$, respectively. The efficiency of irrigation water could also be enhanced with the economic and ecological benefits per unit water being raised and the water consumption per unit land being reduced. The comparisons of the MOFRP model to four alternatives validated that it was capable of achieving satisfactory benefits and reducing system-violation risks without neglecting valuable uncertain information and ecological services of crops. The proposed method was also applicable to other multi-objective management problems under uncertainty without loss of generality.
\end{abstract}

Keywords: water resources; land use; multi-objective optimization; uncertainty; crop planting structure

\section{Introduction}

Water scarcity has been a common issue in many areas worldwide due to rapid population growth and leaping economic development. Soaring population has led to an ever-increasing demand for food and farmland expansion, which are hard to be supported by physically limited natural resources. Among the water-consuming sectors, agriculture accounts for $70 \%$ of the total water use worldwide [1]. In semi-arid and arid areas which heavily rely on irrigated agriculture, the role of agricultural water is even more critical. For example, the share of water used for agriculture reached as much as over $90 \%$ in the desert oases of northwestern China, which is one of the most water-starved and ecologically vulnerable regions, nationally and globally $[2,3]$. The focal issue in such arid areas is water deficit, due to poor natural water endowment as well as mismanagement of water and water-related resources. The extreme shortage in water has become the cause of many other issues in these areas, such as slower economic development and the deterioration of the ecological environment. It triggered streamflow 
dry-up, groundwater table decline, desertification and salinization, which impaired ecological health and thus caused a vicious cycle.

Given that the competition of land and water within the agricultural sector and other sectors is tight, the link between water resources, land use, food security, and ecological health is inevitable $[4,5]$. To ease escalating water shortages and ecological deteriorations, conjunctive management of water and agricultural land are now considered as the most important and effective ways to mitigate these problems [6,7]. Agricultural water and land use not only control the ecosystem's patterns, but also affect the sustainability of local society, economy, and environment [7]. New strategies and management options are required to address water utilization, land use and productivity of agricultural systems. Restructuring agricultural production through highly efficient use of agricultural water and land resources under multiple objectives is thus highly desired.

Over the last a few decades, there have been a number of publications on the optimal use of agricultural water and land resources in irrigated areas, most of which were based on optimization models [6,8-10]. In those studies, a wide spectrum of optimization techniques were used, such as linear programming, non-linear programming, dynamic programming, mixed-integer programming, and multi-objective programming. Among these methods, linear programming-based methods have been extensively used due to their high computational efficiency and easy application to large-scale problems [11-15]. The management of agricultural land and water resources is a complex problem with multi-faceted implications on the economy, society and eco-environment. There exist a number of paralleled objectives to fulfill non-commensurable criteria, which encompass an array of factors such as economic return, productivity, water quality, ecological services, pollution mitigation, labor reduction and job creation. Therefore, multi-objective programming has been playing a prominent role in the management of agricultural water and land resources to sustain economic and social development while maintaining ecological integrity. For instance, Groot et al. coupled a bio-economic farm model with a multi-objective optimization algorithm to support the design and reconfiguration of farming systems under productive and environmental objectives [16]. Kennedy et al. proposed a multi-objective programming model to optimize agricultural profit, biodiversity and freshwater quality through decision-making in land use change [17]. Davijani et al. developed a multi-objective model for supporting the allocation of water resources to agricultural and other sectors in arid regions under economic and job-creation objectives [18]. Galán-Martín et al. formulated a multi-objective linear programming model to optimize the allocation of rainfed and irrigated cropping areas with the objectives of maximized crop production and minimized environmental impact from water consumption [19]. Those studies have verified that multi-objective optimization methods could be effective tools for addressing water- and land-related problems in irrigated areas.

However, major challenges still remained for multi-objective planning of water and land resources in agriculture systems. Firstly, most of the previous work taking ecological factors into account have focused on adverse ecological impacts of crop production or regarded crop cultivation as a barrier to save water for ecological use. It was neglected that, as part of the vegetation cover in the ecosystem, crops could also provide their ecological services. Reconfiguration of crop cultivation structures for the sake of maximized ecological functions could be highly valuable for ecological restoration while ensuring food security. Secondly, the vague and ambiguous information associated with preferences, priorities and various parameters in agricultural decision-making has not been effectively tackled by the previous multi-objective programming methods. The most common multi-objective optimization approach is the weighted sum method which is able to provide a single set of optimal solutions. Normally, the primary task of such a method is to articulate preferences over or priorities of issues, such as the importance of different objectives and attributes [20,21]. Such articulation of preferences and priorities are uncertain in nature without precise boundaries, which can usually be modeled as fuzzy membership grades. As well, many parameters which are of significance for the success of modeling efforts, such as crop water demand and water availability, are hard to be known as deterministic values due to natural variability and measuring limitations [22-26]. The incapability of 
previous multi-objective programming models in reflecting uncertainties would lead to significant risks of system violation.

To overcome the prescribed shortcomings, the objectives of this research aimed at establishing a multi-objective fuzzy-robust programming (MOFRP) method for supporting the optimal use of land and water resources in agriculture. An ecological objective has been incorporated within this model to maximize ecological functions of cultivated crops through the reconfiguration of crop cultivation patterns. Meanwhile, membership grades in relation to importance of objectives and to goodness of crop comprehensive benefits, as well as fuzzy information in the model parameters could be conjunctively tackled. The MOFRP method was then applied to a real-world case in the arid region of China, where the problems of water scarcity and ecological deterioration are prominent. Optimal plans regarding crop cultivation reconfiguration were generated, which suggested that cotton, corn and wheat should be the three most cultivated crops in the study area. Compared to the status quo, the optimized plan would increase economic and ecological benefits by $12.2 \%$ and $18.8 \%$, respectively, within the limit of available irrigation water.

This paper is organized as follows: the development of the MOFRP method is introduced in Section 2; Section 3 presents the application of the model including the study problem and model formulation; the interpretation and analyses of results as well as the comparison of the developed model to alternatives are presented in Section 4; and Section 5 includes the concluding remarks.

\section{Methodology}

A general formula of the MOFRP model is developed as follows:

$$
\operatorname{Max} F(\mathrm{x})=\left(f_{1}(x), f_{2}(x), \ldots, f_{t}(x)\right)^{T}
$$

subject to:

$$
\begin{gathered}
\widetilde{A} X \leq \widetilde{B} \\
X \geq 0
\end{gathered}
$$

where $x=\left(x_{1}, x_{2}, \ldots, x_{\mathrm{n}}\right)^{\mathrm{T}} ; \widetilde{A} \in\{\Re\}^{m \times n} ; \widetilde{B} \in\{\Re\}^{m \times 1} ; \mathrm{X} \in\{\mathrm{R}\}^{n \times 1} ; \Re$ denotes a set of fuzzy variables and parameters; $\mathrm{R}$ denotes a set of deterministic number; $t$ denotes the number of objectives, and $t \geq 2$.

A solution algorithm is also proposed to solve the MOFRP model. There are mainly two steps involved in the solution method. In the first step, the multi-objective problem is converted into a single-objective one based on relative membership grades. Relative membership grades deprived from fuzzy sets theory are used to cope with the uncertainties lying in objective priorities and attribute designation. In the second step, fuzzy constraints are transformed into deterministic ones through tackling fuzziness in the parameters based on the concept of level sets of fuzzy sets. Through these two major steps, the MOFRP model can then be converted into a conventional linear problem which has a single set of global optimum results.

In the first step, the concept of relative membership degrees is introduced to avoid the subjectivity in determining fuzzy membership grades for specified attributes [27]. Consider a multi-objective problem with a vector of decision variables $X$, in which $I$ is the index for the number of objectives, and $J$ is the index for the number of decision variables. The fuzzy membership grades of objectives in relation to "important" are first determined and then normalized as weights $w(i)$. The fuzzy membership grades of options (such as crops) with regard to "good comprehensive benefit" are then calculated based on the objective weights, which can be denoted as a comprehensive benefit coefficient $\left(u_{j}\right)$. The following procedures can be followed to transform the multi-objective problem into a single-objective one:

i. $\quad$ Obtain the matrix of relative membership grades $\mathrm{R}=\left(r_{i j}\right)_{m \times n^{\prime}}$, where $r_{i j}$ is defined as the relative membership grade. $r_{i j}=x_{i j} / \max x_{j}$ corresponds to bigger means better indexes, and $r_{i j}=\min x_{i j} / x_{j}$ corresponds to smaller means better indexes;

ii. Obtain the transposed matrix of $\mathrm{R}=\left(r_{i j}\right)_{m \times n^{\prime}}$, that is, $\mathrm{W}=R^{T}=\left(w_{j i}\right)_{n \times m^{\prime}}$; 
iii. Calculate non-normalized weighting vectors as follows:

$$
w(i)=\frac{1}{1+\left[\sum_{j}^{J}\left(1-w_{j i}\right)^{p} / \sum_{j=1}^{J} w_{j i}^{p}\right]^{\frac{2}{p}}}
$$

where $p$ is the distance parameter, in which $p=1$ means Hamming distance and $p=2$ means Euclidean distance. In this paper, $p=2$.

iv. Calculate the maximum relative membership grade for the comprehensive benefits of sample $j$, which is named as the comprehensive benefit coefficient $\left(u_{j}\right)$ as follows:

$$
u_{j}=\frac{1}{1+\left\{\sum_{i=1}^{m}\left[w_{i}\left(r_{i j}-1\right)\right]^{p} / \sum_{i=1}^{m}\left(w_{i} r_{i j}\right)^{p}\right\}^{\frac{2}{p}}}
$$

where $w_{i}$ is the normalized weight, $\mathbf{w}=\left(w_{1}, w_{2}, \ldots, w_{m}\right)$, and $\sum_{i=1}^{m} w_{i}=1$.

v. Transform the multiple objectives into a single one. The following formula can be used to replace Formula (1a):

$$
\operatorname{Max} Z=\sum_{j=1}^{J} u_{j} x_{j}
$$

Following the above procedures, problem (1) is transformed into a single-objective fuzzy linear programming model in the second step. In order to address fuzzy parameters in the constraints, the fuzzy-robust linear programming (FRLP) is introduced. FRLP involves the optimization of a precise objective function subject to a fuzzy decision space delimited by constraints with fuzzy coefficients and fuzzy capacities [28]. Consider a L-R fuzzy set $N$ as follows [28-30]:

$$
\mu_{N}= \begin{cases}F_{L}\left(\frac{u-x}{\beta}\right), & \text { if }-\infty<x<u, \beta>0 \\ 1, & \text { if } x=u \\ F_{R}\left(\frac{x-u}{\delta}\right), & \text { if } u<x<+\infty, \delta>0\end{cases}
$$

where $F_{L}$ and $F_{R}$ are membership functions; $u$ is mean value of fuzzy set $N ; \beta$ and $\delta$ are the left and right spreads of $N$, respectively. Fuzzy set $N$ can then be expressed in the following format [28]:

$$
\mu_{N}= \begin{cases}0, & \text { if } x<\underline{a} \text { or } x>\bar{a} \\ 1, & \text { if } x=u \\ 1-\frac{2|u-x|}{\bar{a}-\underline{a}}, & \text { if } \underline{a}<x<\bar{a}\end{cases}
$$

where $\underline{a}$ and $\bar{a}$ represent the left- and right-hand side values, respectively, as imposed by fuzzy set $N$ under a certain fuzzy $\alpha$-cut level based on the concept of level sets.

Fuzzy constraint (1b) in model (1) can be replaced with $2 k$ deterministic inequalities as shown in (7a) and (7b), where $k$ denotes the number of fuzzy $\alpha$-cut levels. Decision space of model (1) can then be delimited by the following deterministic constraints:

$$
\begin{aligned}
& \sum_{j=1}^{n}\left(\bar{a}_{i j}^{s} x_{j}\right) \leq \bar{b}_{i}^{s}, \quad i=1,2, \ldots, m ; s=1,2, \ldots, k \\
& \sum_{j=1}^{n}\left(\underline{a}_{i j}^{s} x_{j}\right) \geq \underline{b}_{i}^{s}, \quad i=1,2, \ldots, m ; s=1,2, \ldots, k
\end{aligned}
$$


Combining models (4) and (7), model (1) can be converted into a conventional linear programming problem that can be easily solved. The transformed deterministic model is written as follows:

$$
\operatorname{Max} Z=\sum_{j=1}^{J} \mu_{j} x_{j}
$$

subject to:

$$
\begin{gathered}
\sum_{j=1}^{n}\left(\bar{a}_{i j}^{s} x_{j}\right) \leq \bar{b}_{i}^{s}, \quad i=1,2, \ldots, m ; s=1,2, \ldots, k \\
\sum_{j=1}^{n}\left(\underline{a}_{i j}^{s} x_{j}\right) \geq \underline{b}_{i}^{s}, \quad i=1,2, \ldots, m ; s=1,2, \ldots, k \\
x_{j} \geq 0, \quad j=1,2, \ldots, n
\end{gathered}
$$

Through solving model (8), optimal solutions of decision variable $x_{j}$ can be obtained. Correspondingly, the optimal objective value of objective functions from $f_{1}(x)$ to $f_{t}(x)$ can thus be obtained. In this sense, the final optimal solutions of model (1) are acquired.

\section{Application}

\subsection{Study Area and Problem Statement}

Minqin County lies in the arid regions of northwestern China (Figure 1). Being surrounded by the Badain Jaran and Tengger Deserts in the west, north and east, Minqin has a typical continental desert climate, which is characterized by low and temporally uneven precipitation with an annual average of $127.7 \mathrm{~mm}$, and high evaporation with an annual average as much as $2623 \mathrm{~mm}$. The total population reached 274,300 by the end of 2013. Minqin is located in the downstream alluvial plain of the Shiyang River which is a typical inland river. In average, the total water resources in the Shiyang River Basin is $1.661 \times 10^{9} \mathrm{~m}^{3}$, including streamflow of $1.561 \times 10^{9} \mathrm{~m}^{3}$ and groundwater recharge of $1.00 \times 10^{8} \mathrm{~m}^{3}[3,31]$. As one of the commodity grain bases in the province, Minqin largely relies on irrigated agriculture for its economy. Irrigated land within Minqin County covers an area of about $2000 \mathrm{~km}^{2}$, which is comprised of the Hongyashan, Nanhu, Changning, and along-river irrigation areas.

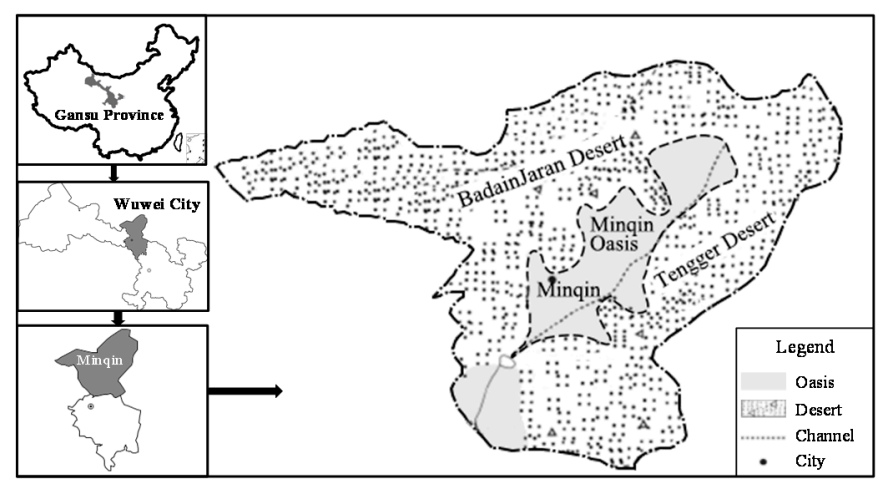

Figure 1. Study area.

The study area suffers from the most serious water shortages and the worst ecological and environmental deteriorations in China. Most of the economic, social and ecological problems in Minqin can, to some extent, be attributed to water deficits and the mismanagement of land and water resources [31]. The runoff flowing into Minqin has been reduced significantly due to the excessive water use in the upper reaches of the Shiyang River, whereas irrigated farmland in Minqin Oasis have expanded greatly. This has led to increasing water supply-demand contradictions among multiple 
users. Agricultural water used to account for over $90 \%$ of the total water use in the early 2000 s, leaving virtually nothing for environment health and ecosystem services [1,7]. Moreover, the cropping structure was unreasonable. The planting areas of water-intensive crops, such as spring wheat, was very high. Consequently, both surface water and groundwater has been over-exploited, leading to the dry up of many tributaries (and even the mainstream), major decline in the groundwater table, degeneration of natural vegetation covers, shrink of wetlands and arable farmland, as well as escalation of desertification and salinization (Chen et al. 2011). Minqin has been identified as one of the most ecologically vulnerable areas in the world [7,32]. Such issues in Minqin pose great challenges to local development and the ecological integrity of the whole country.

To alleviate water shortage and ecological deteriorations in Minqin, land use and water resources management are considered as the most important and effective ways to mitigate the problems. Restructuring agricultural production through optimal use of agricultural water and land resources can play a critical role in preventing desert encroachment and restoring ecological barriers for the adjacent and other regions. It can also promote social and economic development through alleviating the escalating contradictions between the supply and demand of water resources. Therefore, the MOFRP approach was considered suitable for this case, and a MOFRP model was thus established for generating robust cultivation plans in Minqin under uncertainty and multiple objectives.

\subsection{Data Source and Processing}

Extensive data with economic, agronomic, ecological, social, geographic and hydrological implications were collected from records of monitoring stations, field trips and sampling, and a comprehensive review of relevant literature and reports. The main literature referred to included 2010-2020 Shiyang River Basin Management Plan (2007), Wuwei Yearbook (2015), Gansu Statistical Yearbook (2015), Compilation of Statistical Data on the Economic and Social Development of Minqin County (2015) and Food Guidebook for Chinese Inhabitants (2007). The collected data were then supplemented by estimations by expert consultation.

Wheat, corn, cotton, sunflowers, melons and vegetables were dominant crops cultivated in the study area, occupying over $80 \%$ of the total farmland. Table 1 displays the unit yields, costs, prices, per capita demands, water consumption and cultivation areas of these six types of crops in 2015. The minimum allowable and maximum potential areas for cultivating these crops are also listed in Table 1. The maximum areas of crops were mainly identified under the consideration of farmland arability, while the minimum areas were primarily set as their respective lowest historical cultivation areas recorded in local yearbooks from 2002 to 2015. The multiple cropping index in the study area is approximately 1.28. Agricultural water use accounts for approximately $75 \%$ of the total amount of available water resources in the study area. The current water use efficiency coefficient in this irrigation district is 0.61 . As the study area covers a large area that consists of four irrigation areas, there existed heterogeneous conditions. In this study, arithmetic means of the collected data were calculated to obtain the average values of parameters.

Parameters of water availability and irrigation quotas are uncertain in nature due to spatial and temporal variations. In the absence of ample observations, their values can merely be estimated by experts as vague and ambiguous information. Considering the quality of available data in this study case, such parameters were expressed as triangular fuzzy sets. Fuzzy $\alpha$-cut levels of $0.2,0.5$ and 0.8 that represented the lower, middle and higher values of fuzzy membership grades, respectively, were considered for all the fuzzy parameters in this study [33-35]. Figure 2 shows the total amount of available water resources expressed as fuzzy sets. 
Table 1. Crop-related parameters.

\begin{tabular}{ccccccc}
\hline Crop & Wheat & Corn & Cotton & Sunflowers & Melons & Vegetables \\
\hline Yield $\left(\mathrm{kg} / \mathrm{hm}^{2}\right)$ & 7695 & 10,544 & 1800 & 5566 & 6532 & 54,462 \\
Cost $\left(\mathrm{yuan} / \mathrm{hm}^{2}\right)$ & 5250 & 9520 & 11,340 & 3598 & 13,265 & 21,547 \\
Price $(\mathrm{yuan} / \mathrm{kg})$ & 2.09 & 2.36 & 16.40 & 8.41 & 13.71 & 2.29 \\
Demand $(\mathrm{kg} / \mathrm{person})$ & 250 & 350 & 40 & 113 & 72 & 164 \\
Minimum Area $\left(\mathrm{hm}^{2}\right)$ & 5200 & 5000 & 4000 & 3883 & 1973 & 5099 \\
Maximum Area $\left(\mathrm{hm}^{2}\right)$ & 140,000 & 10,452 & 11,856 & 11,650 & 3960 & 7648 \\
Water Consumption $\left(\mathrm{m}^{3} / \mathrm{hm}^{2}\right)$ & 5100 & 5550 & 3900 & 3981 & 3750 & 4750 \\
Current Cultivated Area $\left(\mathrm{hm}^{2}\right)$ & 5473 & 8947 & 5000 & 9513 & 2467 & 2947 \\
\hline
\end{tabular}

Note: 1 yuan $=0.15$ USD according to the average currency conversion rate in 2016.

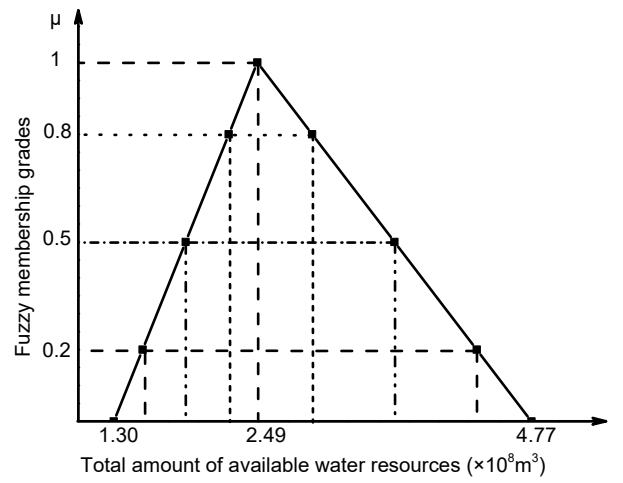

Figure 2. The total available amount of irrigation water.

\subsection{Model Establishment}

A MOFRP model tailored to this study case was developed from a generalization of the local agricultural water resources system and an analysis of the demand, supply, restraints and problems. The planning horizon is one calendar year. Decision variable $x_{j}$ represents the optimal cultivation area of each crop that determines the patterns of land use and water resources allocation.

The objectives of the model were to maximize economic, ecological and social benefits obtained from crop cultivation activities. The economic benefits were calculated as the net income from selling the cultivated crops with the miscellaneous expenditures such as seed purchase and labor being deducted. The ecological objective was to maximize the ecological functions of crops grown at desert oases in terms of sand prevention and wind control. Such ecological functions were calculated based on the hierarchical projections of vegetation coverage [36]. The social benefits were to minimize the amount of irrigation water consumption at fields. The multiple objectives considered in the model can be written as follows:

$$
\begin{gathered}
{\left[\text { Economic Benefits] Max } F_{E C N}=\sum_{j=1}^{J}\left(p_{j}-k_{j}\right) q_{j} x_{j}\right.} \\
{\left[\text { Ecological Benefits] Max } F_{E C L}=\sum_{j=1}^{J} e_{j} \times d_{j} \times x_{j}\right.} \\
{[\text { Social Benefits }] \operatorname{Min} F_{S O C}=\sum_{j=1}^{J} n_{j} x_{j}}
\end{gathered}
$$

where $J$ is the index for crops, $j$ takes value from 1 to 6 that represents wheat, maize, cotton, sunflowers, melons and vegetables, respectively; $F_{E C N}$ is the annual economic benefits from cultivation (yuan); $p_{j}$ is the unit selling price of crop $j$ (yuan $/ \mathrm{kg}$ ); $k_{j}$ is the unit cost for planting crop $j$ (yuan $/ \mathrm{kg}$ ); $q_{j}$ is the average unit yield of crop $j\left(\mathrm{~kg} / \mathrm{hm}^{2}\right) ; F_{E C L}$ is the annual ecological benefits from cultivation 
( $\mathrm{m}^{2}$ coverage); $e_{j}$ is the ecological function values of an individual plant of crop $j$ calculated using the method of layered projections ( $\mathrm{m}^{2}$ coverage/plant); $d_{j}$ is the planting density of crop $j$ (plants $/ \mathrm{hm}^{2}$ ); $F_{S O C}$ is the annual social benefits from cultivation $\left(\mathrm{m}^{3}\right)$; and $n_{j}$ is the net irrigation quota of crop $j$ in the fields $\left(\mathrm{m}^{3} / \mathrm{hm}^{2}\right)$.

The restricting constraints of the model could be roughly classified into two groups: constraints related to land use and those regarding water resources. In detail, constraints of farmland availability, farmland arability, irrigation water availability, food security, and farmer protection were taken into account. The concrete constraints are presented in the following.

(a) Farmland availability constraints

The total area of cultivated crops in the study case should be less than the total available arable area and be more than the minimum area retained for cultivation. Multi-cropping was considered in this study case in response to the administrative policies of promoting the use efficiency of limited land. Correspondingly, the farmland availability constraint is established as follows:

$$
S_{\min } \times R I \leq \sum_{j=1}^{J} x_{j} \leq S_{\max } \times R I
$$

where $S_{\min }$ is the minimum land area used for crop cultivation $\left(\mathrm{hm}^{2}\right) ; S_{\max }$ is the maximum allowable land area for cultivation $\left(\mathrm{hm}^{2}\right)$; and $R I$ refers to the multiple cropping index which suggests the total area of cultivated crops divided by the total physical cropping area in the presence of multi-cropping operations.

(b) Farmland arability constraints

Due to the variations in geographical conditions of fields, such as soil properties and sun exposure, not all the fields are suitable for planting all kinds of crops. In some fields, existing arrangements made to facilitate the cultivation of certain crops also need to be retained in order to respect cultivation habits and not to waste previous investments. In this sense, the cultivation area of each type of crop must be within a range. The maximum values were mainly identified under the consideration of farmland arability, while the minimum areas of crops were primarily set according to their respective lowest historical cultivation areas.

$$
S_{j \min } \leq x_{j} \leq S_{j \max } \forall j
$$

where $S_{j \min }$ is the minimum cultivation area of crop $j\left(\mathrm{hm}^{2}\right)$; and $S_{j \max }$ is the maximum arable area of $\operatorname{crop} j\left(\mathrm{hm}^{2}\right)$.

(c) Water availability constraints

Irrigation water is the main water user in the study area. Irrigation water consumption includes the water demand for crop growth as well as the water losses in the course of water delivery within the irrigation districts, such as water intaking, transmission and distribution. The water allocated for irrigation use cannot exceed the total available volume for irrigation as determined by both natural factors and allocation quotas in the study area.

$$
\sum_{j=1}^{J} \widetilde{M}_{j} x_{j} \leq \eta \times \widetilde{Q}
$$

where $\widetilde{M}_{j}$ is the gross irrigation quota (i.e., withdrawn water) of crop $j$ which equals to the net irrigation quota divided by the coefficient (between 0 and 1) indicating irrigation water use efficiency $\left(\mathrm{m}^{3} / \mathrm{hm}^{2}\right)$ considering the water losses at channels; $\eta$ is the percentage of irrigation water in the total amount of renewable water resources that includes streamflow and groundwater recharge; $\widetilde{Q}$ is the total amount 
of available water resources that can be used in the study area, including available surface water and groundwater $\left(\mathrm{m}^{3}\right)$.

(d) Food security constraints

To ensure crop self-sufficiency in this study area, a constraint of food security was introduced into the model. It was formulated based on the total population and average per capita demand for different crops.

$$
x_{j} \times q_{j} \geq D_{j} \times T P \quad \forall j
$$

where $D_{j}$ is the per capita demand of crop $j$ (kg per person); TP is the total population (persons).

(e) Farmer protection constraints

In the past, $90 \%$ of the local population in the study area made a living on agriculture. While the projects for economic structure optimization and ecological restoration are being implemented in this area, there has been a strong desire and need to maintain a population-based minimum cropping area for the sake of sustaining the income of farmers. This leads to a farmer protection constraint as follows:

$$
\sum_{j=1}^{J} x_{j} / T P \geq M A L
$$

where $M A L$ is the minimum area of cultivation land per capita.

(f) Non-negativity constraints

$$
x_{j} \geq 0 \quad \forall j
$$

The above model was then solved through the method developed and described in the section of methodology.

\section{Results and Discussion}

\subsection{Results Analysis and Comparisons with the Status Quo}

Based on the method developed in Section 2, the weights of economic, ecological and social objectives (i.e., membership grades in relation to "important") were determined to be $0.193,0.355$ and 0.452, respectively. As calculated from Equation (3), the membership grades of wheat, corn, cotton, sunflowers, melons and vegetables in relation to "good comprehensive benefits" were $0.779,0.820$, 0.913, 0.848, 0.731 and 0.904, respectively. Model (9) was then transformed and solved to generate optimal plans for crop cultivation in Minqin. Correspondingly, the economic and ecological benefits from irrigated agriculture as well as the amount of irrigation water consumption could be obtained.

The optimized economic return from irrigated agriculture would be 1.34 billion yuan, with a total cultivation area of 38,939 hectares and a total amount of field water consumption at 177.0 million cubic meters. The cultivated areas of wheat, corn, cotton, sunflowers, melons and vegetables would be $7.19,7.34,11.86,5.00,2.45$ and 5.10 thousand hectares, respectively. Of all the crops, cotton would occupy the largest area while melons would be the least popular. This was probably because cotton had the highest comprehensive benefit coefficient while melons had the least. If it were not for cotton and melons, the priority order of the other four crops would not align with the sequence of their respective comprehensive benefit coefficients. For example, vegetables that had the second highest comprehensive benefit coefficient would be the second least cultivated crop. Such results were obtained from complex trade-off analyses automatically conducted by the model over the economic, ecological and water-consuming implications of these crops as well as the availabilities of water and land resources. 
As shown in Figure 3, the order of these crops in terms of ecological benefits and water consumption amount would strictly follow their cultivated areas. The order from the lowest to the highest would be melons, sunflowers, vegetables, wheat, corn and cotton. However, such a sequence does not agree with their relative economic contributions. Wheat would have the lowest economic contribution, while vegetables would be the dominant crop from the perspective of income. This could be attributed to the wide difference between crops in their unit economic return. In detail, with the consumption of $21 \%$ of the irrigation water, wheat would account for $18 \%$ of the total land and ecological benefits, while contributing to only $6 \%$ of the economic benefits. Similarly, corn would use $19 \%$ of the land, consume $23 \%$ of the water, and bring about one fourth of the total ecological benefits, while contributing merely $8 \%$ of the total economic benefits. Accounting for around one third of the total cultivated areas, ecological benefits and water consumption, cotton would bring in $16 \%$ of the economic income. Consuming $11 \%$ of the water and $13 \%$ of the land, the economic and ecological contributions of sunflowers would be $16 \%$ and $9 \%$, respectively. Accounting for a tiny percentage of the total cultivation land, ecological benefits and water consumption, the economic returns from melons would be $14 \%$ of the total. As the dominant economic crop contributing $39 \%$ of the total income, vegetables' share in cultivation land, ecological benefits and water consumption would be $13 \%, 11 \%$ and $14 \%$, respectively. Figure 3 also illustrates the breakdown of comprehensive benefits by crops that were calculated from Equation (8a). It is worth mentioning the optimized values of the economic and ecological objective functions would be 'the greater the better', whereas that of the social objective function based on water consumption amounts would be 'the smaller the better'. In general, cotton would contribute the most comprehensive benefits, followed by corn and then wheat.

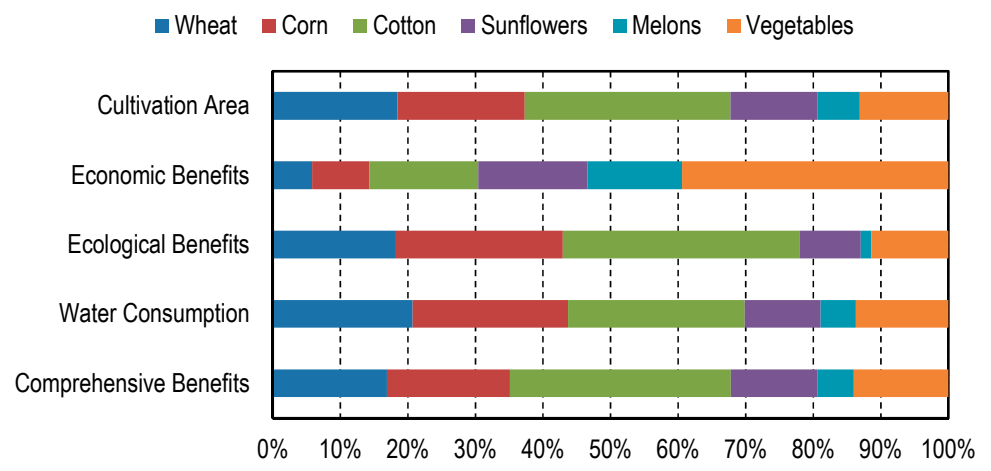

Figure 3. The contribution of different crops to the total cultivation area, economic benefits, ecological benefits, water consumption, and comprehensive benefits.

The generated plans from the MOFRP model were compared to those from the status quo in the benchmark year of 2015. According to the MOFRP model, the study area could accommodate an increase in the cropping area. The total area could be raised to 38,939 hectares, compared to 34,347 hectares for the status quo. Figure 4 illustrates the crop planting structures from the MOFRP model and status quo. If the status quo remains, corn and sunflowers should continue to be the dominant crops in the study area, occupying over half of the total cultivation areas. From the optimized results of the MOFRP model, wheat, corn, cotton, sunflowers, melons and vegetables would account for $18.5 \%, 18.9 \%, 30.4 \%, 12.8 \%, 6.3 \%$ and $13.1 \%$ of the total cultivation area, respectively. This suggests that cotton, corn and wheat would be the three most cultivated crops in the study area. Compared to the status quo, an increase in the cultivated area was observed for wheat, corn and vegetables. In detail, the planting area of wheat would increase from 5.473 to 7.186 thousand hectares, and that of vegetables would increase from 2.947 to 5.099 thousand hectares. The area of cotton would be amplified by over two folds from 5.000 to 11.856 thousand hectares. On the contrary, the areas of corn, sunflowers and melons would be decreased. Sunflowers would experience the sharpest decline among the three crops, changing from 9.513 to 5.001 thousand hectares. The area of corn would drop 
to 7.343 thousand hectares from the status quo of 8.947 thousand hectares. The decline in the area of melons would be minor, which would be merely 12 hectares. Based on the optimal results generated from the MOFRP model, the crop planting structure in Minqin could be adjusted, mainly through enlarging the area of cotton and gradually reducing the area of sunflowers for the sake of maximum comprehensive benefits.

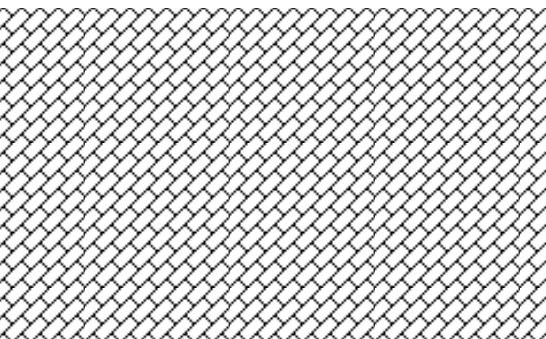

(a)



(b)

Figure 4. Crop planting structure: (a) multi-objective fuzzy-robust programming (MOFRP) model; (b) Status quo.

Figure 5 compares the breakdown of benefits and water consumption between the optimized results and status quo. For the status quo, sunflowers and vegetables would be the first and second contributors to economic benefits. For the results from the MOFRP model, although these two crops would remain as the main economic crops, their rankings would be exchanged. Vegetables would be the dominant contributor, whose contribution would be more than twice of that from sunflowers. Regarding ecological benefits, corn and sunflowers would bring in the most ecological benefits if the status quo is retained. As a result of the MOFRP model, cotton would contribute the most ecological benefits, followed by corn. In terms of water consumption at fields, corn and sunflowers would consume the most for the status quo. According to the MOFRP model results, cotton and corn would be the main water users.

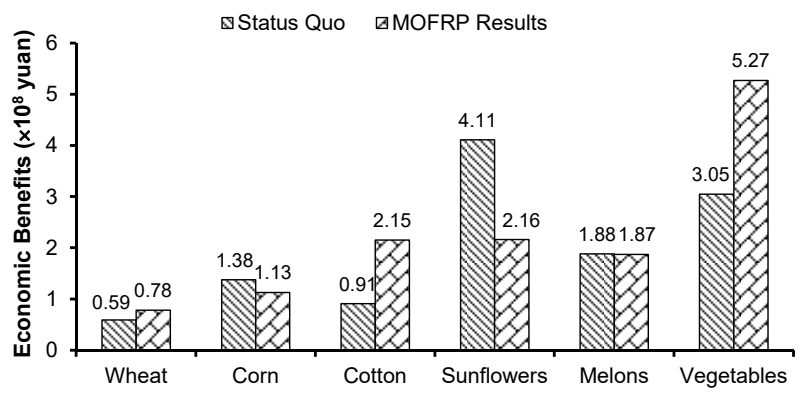

(a)

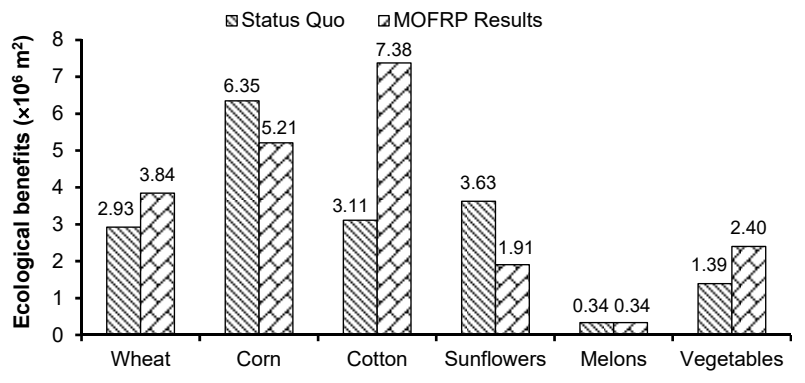

(b)

Figure 5. Cont. 


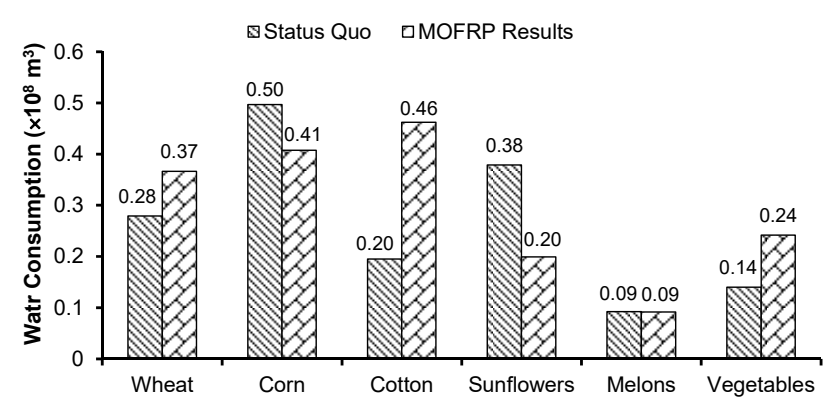

(c)

Figure 5. Comparison of the breakdown of benefits and water consumption between the model results and status quo. (a) Breakdown of economic benefits; (b) Breakdown of ecological benefits and (c) Breakdown of water consumption.

Compared to the status quo, the plans generated by the MOFRP model could enhance the economic and ecological benefits as well as the efficiency of water use in irrigated agriculture in the study area. As shown in Figure 6, the economic benefits could be raised from 1.19 to 1.34 billion yuan, resulting in an increment of $12.2 \%$. Additionally, an increment of $18.8 \%$ in ecological benefits would be realized if the status quo is changed to the operations recommended by the MOFRP model. Meanwhile, the MOFRP model could allow the study area to accommodate $13.4 \%$ more areas of cultivation for greater agricultural development potential, while the total water amount used for irrigation would still be within the carrying capacity of water resources. Although the total water consumption would increase by $11.9 \%$, the water consumption per hectare of cultivated land (illustrated as unit area water consumption in Figure 6) would decrease by $1.3 \%$. Moreover, in the study area, the economic benefits gained from one cubic meter of net irrigation water delivered to farms, which was indicated as unit water economic benefit in Figure 6, would increase by $0.3 \%$. Likewise, the unit water ecological benefit, which indicated the ecological benefits per cubic meter of net irrigation water, would increase by $6.2 \%$. In other words, to achieve certain economic and ecological benefits, $0.3 \%$ and $6.2 \%$ of water would be saved. It could thus be concluded that, the MOFRP model could lead to increased efficiency of water use compared to the current practices at the county scale, which is of great significance for this water-starved area. Compared to the status quo, the unit area ecological benefit, which denotes the ecological benefit gained from one hectare of cultivated land, would increase by $4.8 \%$. The unit area economic benefit expressing the economic benefit per unit cultivated area would decrease by $1.1 \%$. This could be attributed to the fact that the existing practices are heavily focused on the maximization of economic benefits without ecological consequences being considered. Such a slight decline in the unit area economic benefit is minimal considering that land in the study area is relatively plentiful and that the total economic benefits of the entire study area would increase with the optimized plan from the MOFRP model.

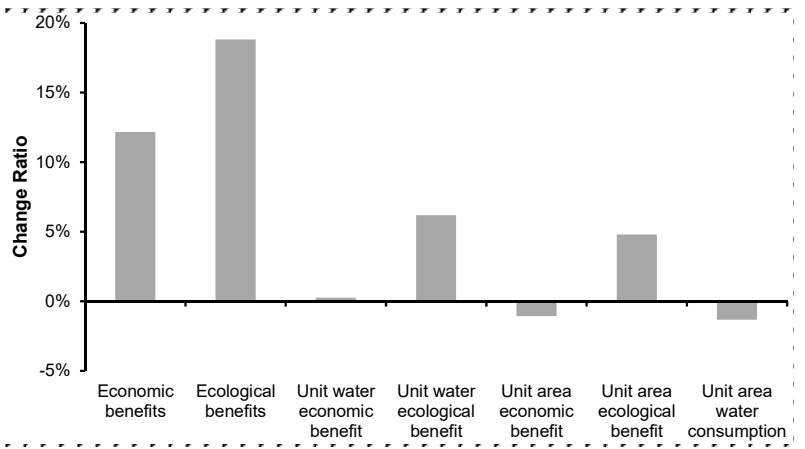

Figure 6. Comparisons of the optimal results from MOFRP with the status quo. 


\subsection{Discussions}

The developed MOFRP model was compared to four alternative models. The first model was a deterministic model referred to as the multi-objective programming (MOP) model which neglected the uncertainty in parameters. The other three models were models with an individual objective, including the environment-oriented fuzzy-robust programming (EnFRP) model with a maximized economic objective, the EoFRP model with a maximized ecological objective, and the society-oriented fuzzy-robust programming (sFRP) model with a social objective for minimized water consumption. Figure 7 compares the MOFRP model to the four alternative models from the aspects of total benefits and unit benefits.

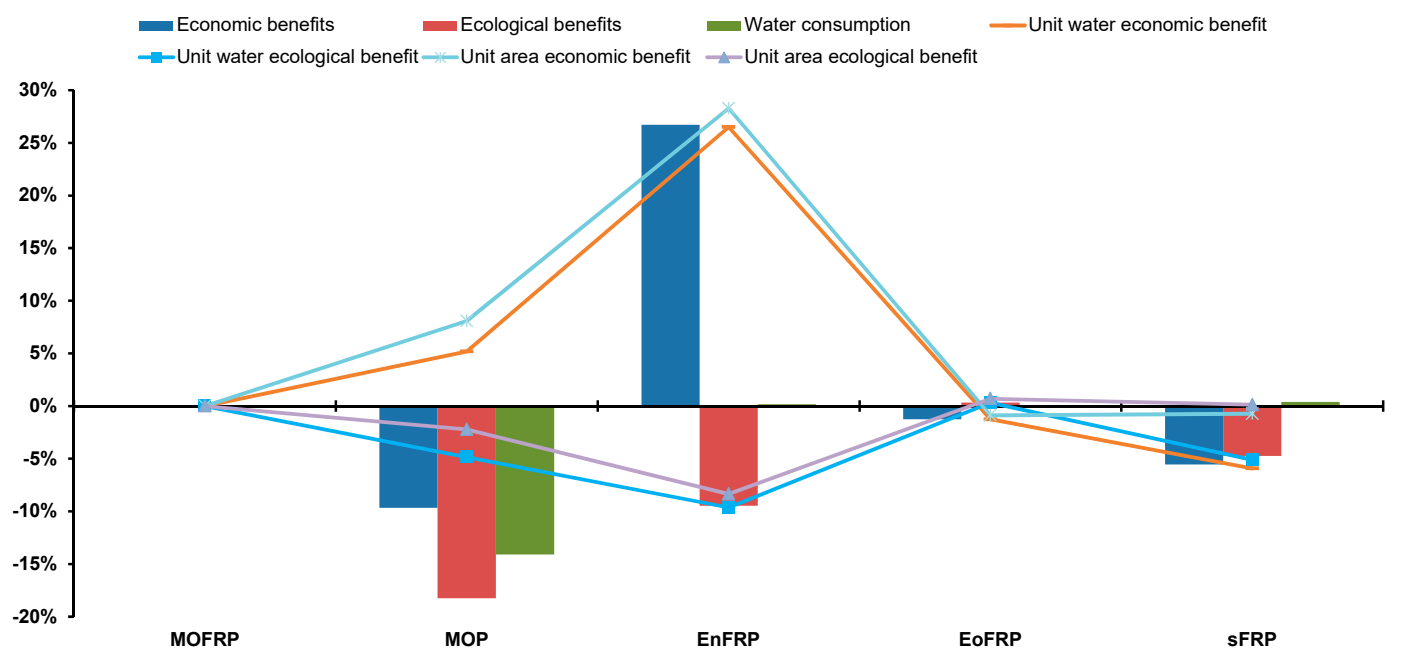

Figure 7. Comparison between the MOFRP model and other alternative models.

Compared to MOFRP, MOP would lose $10 \%$ of the economic benefits and $18 \%$ of the benefits. Although MOP would use 14\% less water, the unit water ecological benefit and unit area ecological benefit would decrease by $5 \%$ and $2 \%$, respectively. The unit water economic benefit and unit area economic benefit from MOP would be 5\% and $8 \%$ higher than MOFRP. The greatest problem that lies in MOP would be the losses of valuable fuzzy information associated with irrigation water demand and water availability. In the contrast, MOFRP would be able to enhance robustness of the model and avoid system violation under data perturbations through realistically reflecting uncertainties.

In comparison with the three single objective models, MOFRP is more robust in nature by analyzing and balancing more facets of the problems, which makes its results more reliable. It was not surprising that EnFRP generated plans with higher total and unit economic benefits due to its sole emphasis on economic objectives. For the same reason, the total and unit ecological benefits of EnFRP would be lost approximately 10\% compared to MOFRP. The results from the ecologically-oriented EoFRP model would not deviate from those of the MOFRP model by $1 \%$ or so. This implies that the ecological factors would affect the results to a great extent, which verifies the necessity to incorporate ecological objectives within the model formulation. In comparison with the sFRP model that has the objective of minimized water consumption, it was interesting to note that MOFRP would save water of $0.4 \%$. Moreover, MOFRP would generate $6 \%$ more total and unit economic benefits as well as $5 \%$ more total and unit ecological benefits.

In this study, the comparisons of benefits and unit benefits between the MOFRP results and the status quo (or its potential alternatives) were undertaken at the county level. The areas of different crops and the associated benefits were determined and compared at the entire county without those at individual farms being specified. It is noteworthy that the effects could be scale-dependent and vary at greater (e.g., provincial) or smaller (e.g., farm) scales. In the future, the model formulation could be easily modified for supporting decision making at other scales. For example, the decision 
variables could be set for determining the cultivation areas of different crops at individual farms. In that case, comparisons could be made at different scales and the scale effects of optimization efforts could be examined.

It is interesting to observe that the optimal areas of crops would not heavily depend on the comprehensive benefits coefficients. Except for cotton and melons, the priority order of the other four crops would not align with the sequence of their respective comprehensive benefit coefficients. This implies that the availabilities of water and arable land would also play an important role in the decision making process as bottleneck resources. Such results also verifies the ability of the MOFRP model to comprehensively analyze and balance the complex trade-offs among different objectives and constraints in a giant system.

In practical applications, the model results can assist the decision makers in making an overarching master plan of crop cultivation structures. Once a master plan is put in place, stakeholders can then work out the farm-specific plans. The adjustment of cultivation patterns should be based on the considerations of multiple factors with technical and social implications, such as heterogonous conditions, existing investments and past practices. On one hand, minimum changes would be favorable when reconfiguring the cultivation patterns. In the MOFRP model, the total cultivation area of each type of crop was required to fall within a range dependent on multiple factors, such as farmland arability and historical values. Therefore, there would not be huge differences between the optimized and past plans or significant technical barriers, which would facilitate the implementation of the optimal plans. On the other hand, the switching of farms to a different cropping pattern through operations such as crop rotations would be helpful for reducing soil erosions, enhancing soil fertility and increasing crop yields. In practice, information technologies such as remote sensing and geographic information systems can also be utilized for determining the spatial layout of crops. Decision support systems integrating the developed model and information technologies have great potential to directly assist the authorities and farmers in making decisions [37]. Moreover, the authorities should encourage and educate farmers to cultivate crops in alignment with the optimized plans for maximizing overall benefits. When necessary, subsidies funded by part of the anticipated revenue increments can be established as economic incentives.

\section{Conclusions}

Most of economic, social and ecological problems are partly, if not mainly, attributed to the scarcity and mismanagement of natural resources, particularly land and water resources. In this study, a multi-objective fuzzy-robust programming (MOFRP) model was developed for supporting the optimal use of land and water resources in agriculture. Remedying the shortcomings of the previous methods, MOFRP gave credits to crop cultivation for its services to the ecological environment and was able to maximize such benefits through restructuring crop cultivation patterns. At the same time, uncertainties in the preferences, priorities and parameters associated with decision making could be effectively reflected, reducing the risk levels of system violation. A solution algorithm for MOFRP has also been proposed.

The developed MOFRP method has been successfully applied to an arid irrigation area in northwestern China which was considered to be one of the most water-scare and ecologically vulnerable areas worldwide. A MOFRP model tailored to the study case was formulated with the goals to maximize economic and ecological benefits and minimize water consumption at fields under physical limitations of water and land resources. In this model, fuzzy membership grades were defined to reflect the importance of different objectives and priorities of different crops in terms of their comprehensive benefits. Additionally, fuzziness associated with the water supply and demand parameters of crops was effectively tackled and incorporated into the modeling process. Optimal plans regarding crop cultivation reconfiguration were generated from the MOFRP model. According to the model results, cotton, corn and wheat should be the three main crops cultivated in the study area. Compared to the status quo, the optimal plans obtained from the MOFRP model could increase the 
economic and ecological benefits by $12.2 \%$ and $18.8 \%$, respectively. As well, the efficiency of irrigation water in the study area could be enhanced by the MOFRP model, with the unit water economic and ecological benefits being raised and the unit area water consumption being reduced. The optimal areas of crops would not align with the sequence of their respective comprehensive benefit coefficients. Such results verified the ability of the MOFRP model to comprehensively analyze and balance the complex trade-offs among different objectives and resources restraints in a giant system.

The results from the MOFRP model were also compared to those from potential alternative models, including one model that neglected the presence of fuzziness in parameters as well as three models that respectively treated one of the three objectives. The compared results verified that the MOFRP model was able to reduce the risks of system violation and achieve satisfactory benefits without neglecting valuable uncertain information and ecological benefits.

In practical applications, the model results could provide decision makers with a master plan of crop cultivation structures, based on which farm-specific plans could be proposed. Information technologies and decision support systems could be very helpful in the decision-making process. Subsidies funded by part of the increased revenues could also be established as an incentive or compensation for farmers to comply with the optimized cultivation plans. The proposed method was also applicable to other multi-objective management plans under uncertainty without loss of generality. Future research could be directed at the exploration of scale effects of optimization efforts.

Acknowledgments: This research was financially supported by the National Key Research and Development Program of China (2016YFC0400207), the National Natural Science Foundation of China (51639009) and the Thousand Talents Program. The authors are grateful to the editor and the anonymous reviewers for their insightful comments and suggestions.

Author Contributions: The first author conceived the idea, managed the research work, and wrote and revised the manuscript. The second author conducted data collection and analysis, and ran the model. The third author assisted in revising the manuscript.

Conflicts of Interest: The authors declare no conflict of interest.

\section{References}

1. Aregay, F.A.; Yao, L.Y.; Zhao, M.J. Spatial preference heterogeneity for integrated river basin management: The case of the Shiyang River basin, China. Sustainability 2016, 8, 970. [CrossRef]

2. Zhou, W.; Li, J.L.; Mu, S.J.; Gang, C.C.; Sun, Z.G. Effects of ecological restoration-induced land-use change and improved management on grassland net primary productivity in the shiyanghe river basin, North-West China. Grass Forage Sci. 2014, 69, 596-610. [CrossRef]

3. Kang, S.Z.; Hao, X.M.; Du, L.; Tong, T.S.; Su, X.L.; Lu, H.N.; Li, X.L.; Huo, Z.L.; Li, S.E.; Ding, R.S. Improving agricultural water productivity to ensure food security in China under changing environment: From research to practice. Agric. Water Manag. 2017, 179, 5-17. [CrossRef]

4. Todorovic, M.; Lamaddalena, N.; Jovanovic, N.; Pereira, L.S. Agricultural water management: Priorities and challenges. Agric. Water Manag. 2015, 147, 1-3. [CrossRef]

5. Rong, Q.Q.; Liu, J.T.; Cai, Y.P.; Lu, Z.H.; Zhao, Z.Z.; Yue, W.C.; Xia, J.B. Leaf carbon, nitrogen and phosphorus stoichiometry of tamarix chinensis lour. In the laizhou bay coastal wetland, China. Ecol. Eng. 2015, 76, 57-65. [CrossRef]

6. Tan, Q.; Huang, G.H.; Cai, Y.P. Radial interval chance-constrained programming for agricultural non-point source water pollution control under uncertainty. Agric. Water Manag. 2011, 98, 1595-1606. [CrossRef]

7. Xue, X.; Liao, J.; Hsing, Y.T.; Huang, C.H.; Liu, F.M. Policies, land use, and water resource management in an arid oasis ecosystem. Environ. Manag. 2015, 55, 1036-1051. [CrossRef] [PubMed]

8. Guo, P.; Chen, X.H.; Tong, L.; Li, J.B.; Li, M. An optimization model for a crop deficit irrigation system under uncertainty. Eng. Optim. 2014, 46, 1-14. [CrossRef]

9. Das, B.; Singh, A.; Panda, S.N.; Yasuda, H. Optimal land and water resources allocation policies for sustainable irrigated agriculture. Land Use Policy 2015, 42, 527-537. [CrossRef] 
10. Schutze, N.; Kloss, S.; Lennartz, F.; al Bakri, A.; Schmitz, G.H. Optimal planning and operation of irrigation systems under water resource constraints in oman considering climatic uncertainty. Environ. Earth Sci. 2012, 65, 1511-1521. [CrossRef]

11. Tan, Q.; Huang, G.H.; Cai, Y.P. Radial-Interval linear programming for environmental management under varied protection levels. J. Air Waste Manag. Assoc. 2010, 60, 1078-1093. [CrossRef] [PubMed]

12. Singh, A. Review: Computer-based models for managing the water-resource problems of irrigated agriculture. Hydrogeol. J. 2015, 23, 1217-1227. [CrossRef]

13. Wang, X.W.; Cai, Y.P.; Xu, Y.; Zhao, H.Z.; Chen, J.J. Optimal strategies for carbon reduction at dual levels in China based on a hybrid nonlinear grey-prediction and quota-allocation model. J. Clean. Prod. 2014, 83, 185-193. [CrossRef]

14. Cai, Y.P.; Huang, G.H.; Yeh, S.C.; Liu, L.; Li, G.C. A modeling approach for investigating climate change impacts on renewable energy utilization. Int. J. Energy Res. 2012, 36, 764-777. [CrossRef]

15. Tan, Q.; Huang, G.H.; Cai, Y.P. A fuzzy evacuation management model oriented toward the mitigation of emissions. J. Environ. Inf. 2015, 25, 117-125. [CrossRef]

16. Groot, J.C.J.; Oomen, G.J.M.; Rossing, W.A.H. Multi-objective optimization and design of farming systems. Agric. Syst. 2012, 110, 63-77. [CrossRef]

17. Kennedy, C.M.; Hawthorne, P.L.; Miteva, D.A.; Baumgarten, L.; Sochi, K.; Matsumoto, M.; Evans, J.S.; Polasky, S.; Hamel, P.; Vieira, E.M.; et al. Optimizing land use decision-making to sustain brazilian agricultural profits, biodiversity and ecosystem services. Biol. Conserv. 2016, 204, 221-230. [CrossRef]

18. Davijani, M.H.; Banihabib, M.E.; Anvar, A.N.; Hashemi, S.R. Multi-objective optimization model for the allocation of water resources in arid regions based on the maximization of socioeconomic efficiency. Water Resour. Manag. 2016, 30, 927-946. [CrossRef]

19. Galan-Martin, A.; Vaskan, P.; Anton, A.; Esteller, L.J.; Guillen-Gosalbez, G. Multi-objective optimization of rainfed and irrigated agricultural areas considering production and environmental criteria: A case study of wheat production in Spain. J. Clean. Prod. 2017, 140, 816-830. [CrossRef]

20. Marler, R.T.; Arora, J.S. Survey of multi-objective optimization methods for engineering. Struct. Multidiscip. Optim. 2004, 26, 369-395. [CrossRef]

21. Marler, R.T.; Arora, J.S. The weighted sum method for multi-objective optimization: New insights. Struct. Multidiscip. Optim. 2010, 41, 853-862. [CrossRef]

22. Tan, Q.; Huang, G.H.; Cai, Y.P. Multi-source multi-sector sustainable water supply under multiple uncertainties: An inexact fuzzy-stochastic quadratic programming approach. Water Resour. Manag. 2013, 27, 451-473. [CrossRef]

23. Cai, Y.P.; Huang, G.H.; Wang, X.; Li, G.C.; Tan, Q. An inexact programming approach for supporting ecologically sustainable water supply with the consideration of uncertain water demand by ecosystems. Stoch. Environ. Res. Risk Assess. 2011, 25, 721-735. [CrossRef]

24. Wang, R.; Li, Y.; Tan, Q. A review of inexact optimization modeling and its application to integrated water resources management. Front. Earth Sci. 2015, 9, 51-64. [CrossRef]

25. Zeng, X.T.; Kang, S.Z.; Li, F.S.; Zhang, L.; Guo, P. Fuzzy multi-objective linear programming applying to crop area planning. Agric. Water Manag. 2010, 98, 134-142. [CrossRef]

26. Yue, W.C.; Cai, Y.P.; Rong, Q.Q.; Li, C.H.; Ren, L.J. A hybrid life-cycle and fuzzy-set-pair analyses approach for comprehensively evaluating impacts of industrial wastewater under uncertainty. J. Clean. Prod. 2014, 80, 57-68. [CrossRef]

27. Chen, S.Y.; Ma, J.Q.; Zhang, Z.W. A multi-objective fuzzy optimization model for planting structure and its method. J. Dalian Univ. Technol. 2003, 43, 12-15.

28. Leung, Y. Spatial Analysis and Planning under Imprecision; Studies in Regional Science and Urban Economics; North-Holland Publishing Co.: Amsterdam, The Netherlands; New York, NY, USA, 1988.

29. Inuiguchi, M.; Sakawa, M. Robust optimization under softness in a fuzzy linear programming problem. Int. J. Approx. Reason. 1998, 18, 21-34. [CrossRef]

30. Dubois, D.; Prade, H. Operations on fuzzy numbers. Int. J. Syst. Sci. 1978, 9, 613-626. [CrossRef]

31. Li, Z.; Quan, J.; Li, X.Y.; Wu, X.C.; Wu, H.W.; Li, Y.T.; Li, G.Y. Establishing a model of conjunctive regulation of surface water and groundwater in the arid regions. Agric. Water Manag. 2016, 174, 30-38. [CrossRef] 
32. Feng, Q.; Miao, Z.; Li, Z.X.; Li, J.G.; Si, J.H.; Yonghong, S.; Chang, Z.Q. Public perception of an ecological rehabilitation project in inland river basins in Northern China: Success or failure. Environ. Res. 2015, 139, 20-30. [CrossRef] [PubMed]

33. Nie, X.H.; Huang, G.H.; Li, Y.P.; Liu, L. Ifrp: A hybrid interval-parameter fuzzy robust programming approach for waste management planning under uncertainty. J. Environ. Manag. 2007, 84, 1-11. [CrossRef] [PubMed]

34. Tan, Q.; Huang, G.H.; Wu, C.Z.; Cai, Y.P. If-Em: An interval-parameter fuzzy linear programming model for environment-oriented evacuation planning under uncertainty. J. Adv. Transp. 2011, 45, 286-303. [CrossRef]

35. Cai, Y.P.; Huang, G.H.; Tan, Q.; Liu, L. An integrated approach for climate-change impact analysis and adaptation planning under multi-level uncertainties. Part II. Case study. Renew. Sustain. Energy Rev. 2011, 15, 3051-3073. [CrossRef]

36. Chang, Z.F.; Wang, D.W.; Duan, X.F.; Wang, Q.Q.; Zhang, J.H.; Yang, M. Relative ecological values of several major plants in minqin desert area. J. Arid Land Resour. Environ. 2015, 29, 86-91.

37. Cai, Y.P.; Huang, G.H.; Yang, Z.F.; Sun, W.; Chen, B. Investigation of public's perception towards rural sustainable development based on a two-level expert system. Expert Syst. Appl. 2009, 36, 8910-8924. [CrossRef]

(C) 2017 by the authors. Licensee MDPI, Basel, Switzerland. This article is an open access article distributed under the terms and conditions of the Creative Commons Attribution (CC BY) license (http://creativecommons.org/licenses/by/4.0/). 